\title{
Bulaşıcı Olmayan Hastalık Mortalite Oranları ile İnsani Gelişmişsik Endeksi ve Küresel Cinsiyet Uçurumu Endeksi arasındaki İlişki
}

\author{
Relationship Between Noncommunicable Disease Mortality Rates with Human Development Index and Global \\ Gender Gap Index
}

\author{
Elif Nur YILDIRIM ÖZTÜRK ${ }^{1}$, Mehmet UYAR ${ }^{2}$
}

\section{$\ddot{O Z Z}$}

$\mathrm{Bu}$ araştırmada; ülkelerin Bulaşıcı Olmayan Hastalık (BOH) mortalite oranlarının İnsani Gelişmişlik Endeksi (IGE) ve Küresel Cinsiyet Uçurumu Endeksi (KCUE) ile ilişkisinin varlığının ve boyutunun değerlendirilmesi amaçlanmıştır.

Araştırma tanımlayıcı türdedir. Araştırma kapsamında kullanılan veriler Dünya Sağlık Örgütü tarafından açıklanan BOH Raporu'ndan, Birleşmiş Milletler'in IGE verilerinden ve Dünya Ekonomik Forumu'nun KCUE verilerinden elde edilmiştir. Araştırmada kullanılan verilerin tamamı 2016 yılına aittir. Karşılaştırmalarda kullanılması planlanan verilerin tamamına sahip olan 140 ülke araştırma kapsamına alınmıştır. Analizler sırasında ortalama, standart sapma, minimum ve maksimum değerleri sayısal verileri özetlemede kullanılmıştır. Çalışmada; BOH mortalite oranları ile IGE ve KCUE arasındaki ilişki Spearman Korelasyon katsayısı ile incelenmiştir. P'nin 0,05'ten küçük olduğu durumlar istatistiksel açıdan anlamlı kabul edilmiştir.

Toplam 140 ülkenin $\mathrm{BOH}$ mortalite oranlar1 ortalamas1 \%72,385 $\pm 20,758$ (Min:27, Max:95) idi. En düşük BOH mortalite oranına sahip olanlar Çad, Angola, Kenya ve Mozambik iken; en yüksek orana sahip olan ülkeler Bulgaristan, Sirbistan ve Karadağ'dır. Ülkelerin BOH mortalite oranları ile IGE arasında pozitif yönlü, kuvvetli düzeyde ve anlamlı ilişki saptanmıştır $(r=0,781, p<0,001)$. BOH mortalite oranları ile KCUE arasında pozitif yönlü, zayıf düzeyde ve anlamlı ilişki saptanmıştır ( $\mathrm{r}=0,323, \mathrm{p}<0,001)$.

İnsani gelişmişlik arttıkça ve küresel cinsiyet eşitsizliği azaldıkça; $\mathrm{BOH}$ mortalitesinin arttığ bulunmuştur. $\mathrm{Bu}$ durumu değiştirmek için multisektöriyel ve multidisipliner önlemler hayata geçirilmelidir.

Anahtar Kelimeler: Bulaşıcı Olmayan Hastalık,İnsani Gelişmişlik, Küresel Cinsiyet Uçurumu.

\section{ABSTRACT}

The aim of this study is to evaluate the presence and extent of the relationship between countries' Noncommunicable Disease (NCD) mortality rates with the Human Development Index (HDI) and Global Gender Gap Index (GGGI).

The study type is descriptive. The data used in the research are obtained from the NCD Report of World Health Organization, HDI data of United Nations and GGGI data of World Economic Forum. All of the data used in the research belongs to 2016. 140 countries with all the data planned to be used in the comparisons are included in the study. Mean, Standard deviation, minimum and maximum values are used to summarize the numerical data during the analyzes. In this study, the relationship between NCD mortality rates with HDI and GGGI is investigated with Spearman Correlation Coefficient. $\quad \mathrm{P}<0.05$ is considered statistically significant.

The average mortality rate of $\mathrm{NCD}$ in 140 countriesis 72.385 \pm 20.758 (Min: 27, Max: 95). Chad, Angola, Kenya and Mozambique have the lowest NCD mortality rate; the countries with the highest rates are Bulgaria, Serbia and Montenegro. There is a positive, strong and significant relationship between the NCD mortality rates and HDI $(\mathrm{r}=0.781, \mathrm{p}<0.001)$. There is a positive, weak and significant relationship between NCD mortality rates and GGGI $(r=0.323, \mathrm{p}<0.001)$.

It is found that NCD mortality increased as human development increased and global gender inequality decreased. Multisectoral and multidisciplinary measures should be implemented to change this situation.

Keywords: Noncommunicable Disease, Human Development, Global Gender Gap.

${ }^{1}$ Uzm. Dr., Halk Sağlığı Uzmanı, Necmettin Erbakan Üniversitesi Meram Tıp Fakültesi Halk Sağlığı ABD, elifnyildirim@ hotmail.com, ORCID: 0000-0003-1447-9756

${ }^{2}$ Dr. Öğr. Üyesi, Halk Sağlığı Uzmanı, Necmettin Erbakan Üniversitesi Meram Tıp Fakültesi Halk Sağlığı ABD, mehmetuyardr@hotmail.com, ORCID: 0000-0002-3954-7471

İletişim / Corresponding Author: $\quad$ Elif Nur YILDIRIM ÖZTÜRK

Geliș Tarihi / Received:

09.03.2020

e-posta/e-mail:

elifnyildirim@hotmail.com

Kabul Tarihi/Accepted:

23.06 .2020 


\section{GíRIŞ}

Toplumların sağlık düzeyi, değişik türden belirleyicilerin kompleks etkileşimleri tarafindan belirlenmektedir. Cinsiyet, yaşam tarzı, fizik çevre, eğitim, iş ve çalışma koşulları, gelir durumu, sosyal statü ve sağlık hizmetlerine ulaşım gibi değişkenler sağlığın sosyal belirleyicilerini meydana getirmektedir. $\mathrm{Bu}$ belirleyiciler, hastalıklarla/sağlığı etkileyen durumlarla ilişkilendirilmekte ve perde arkasında bulunan nedenler olarak dikkati çekmektedir. ${ }^{1,2}$

Sağlığın sosyal belirleyicilerinin toplumlar içinde, hatta aynı toplumun farklı bölgelerinde homojen olmayan dağılımı eşitsizliklere neden olmaktadır. ${ }^{3,4}$ Sağlıkla bağlantılı eşitsizlik; insan haklarına, toplumsal firsatlara, kurumlara eşit ulaşılamaması; bu firsatların eşit kullanılamaması olarak tanımlanabilir. ${ }^{5,6}$

Hastalıkların/sağlığ etkileyen durumların ortaya çıkmasında etkili olan nedenler incelendiğinde toplum sağlığının \%50'sinin sosyoekonomik çevreye, \%25'inin tedavi edici sağlık hizmetlerine, \%15'inin biyolojik ve genetik faktörlere, \%10'unun ise fizik çevreye bağl1 olduğu gösterilmiştir. ${ }^{7-9}$

Toplumda sık görülen, çok sayıda ölüm, sakatlık ve iş gücü kaybına yol açan hastalıklara halk sağlığı açısından önemli hastalık/durum adı verilmektedir. ${ }^{10}$ Dünya Sağlık Örgütü'nün (DSÖ), Dünya çapında en fazla ölüme neden olan on hastalı/durum ve kaba ölüm hızları ile ilgili verisi Tablo 1'de gösterilmiştir. ${ }^{11,12}$

Tablo 1.Dünya Çapında En Fazla Ölüme Neden Olan On Hastalık/Durum ve Bunlardan Etkilenen Kişi Sayısı

\begin{tabular}{clc}
\hline Sıra No & Ölüm Nedeni & $\begin{array}{c}\text { Kaba Ölüm Hızi } \\
(\mathbf{1 0 0 . 0 0 0} \text { kişide })\end{array}$ \\
\hline $\mathbf{1}$ & İskemikKalp Hastalıkları & 126 \\
\hline $\mathbf{2}$ & İnme & 77 \\
\hline $\mathbf{3}$ & Kronik Obstruktif Akciğer Hastalıkları & 41 \\
\hline $\mathbf{4}$ & Alt Solunum Yolu Enfeksiyonları & 40 \\
\hline $\mathbf{5}$ & Alzheimer Ve Diğer Demanslar & 27 \\
\hline $\mathbf{6}$ & Trakea, Bronş Ve Akciğer Kanserleri & 23 \\
\hline $\mathbf{7}$ & DiabetesMellitus & 21 \\
\hline $\mathbf{8}$ & Trafik Kazaları & 19 \\
\hline $\mathbf{9}$ & Diare & 19 \\
\hline $\mathbf{1 0}$ & Tüberküloz & 17 \\
\hline
\end{tabular}

DSÖ'nün açıkladığı bu on hastalığın/durumun her biri önemli birer sağlık sorunu olmakla beraber bulaşıcı olmayan hastalık $(\mathrm{BOH})$ nedenli ölümlerin tüm ölümler içinde ön planda olduğu görülmektedir. Dünya genelinde meydana gelen ölümlerin $\% 71$ 'i $\mathrm{BOH}$ nedeniyle olmaktadır. ${ }^{13}$

Günümüzde gelişmiş ülkeler $\mathrm{BOH}$ ile mücadele ederken, gelişmemiş ülkeler hala ağırlıklı olarak bulaşıcı hastalıklar ile mücadele etmektedir. Gelişmekte olan ülkelerde ise çifte hastalık yükü söz konusudur. ${ }^{3}$
$\mathrm{BOH}$ da dâhil olmak üzere sağlığ1 ilgilendiren olay ve durumlar sağlığın sosyal belirleyicilerinin, dolayısıyla da hem ekonomik durumun ve insani gelişmişliğin hem de toplumsal cinsiyet eşitsizliğinin etkisi altındadır. ${ }^{14,15}$

$\mathrm{Bu}$ araştırmada; ülkelerin $\mathrm{BOH}$ mortalite oranlarının İnsani Gelişmişlik Endeksi (IGE) ve Küresel Cinsiyet Uçurumu Endeksi (KCUE) ile ilişkisinin varlığının ve boyutunun değerlendirilmesi ve sık görülen hastalıkların/sağlık sorunlarının eşitsizliklerle ilişkisine dikkat çekilmesi amaçlanmıştır. 


\section{MATERYAL VE METOT}

\section{Araştırmanın Türü}

Araştırma kamuya açık olarak sunulan verilerin sekonder analizlerini içeren tanımlayıcı bir çalışma olarak tasarlanmıştır.

\section{Araștırmanın Verileri}

Araştırma sürecinde kullanılan veriler DSÖ tarafından açıklanan BOH Raporu'ndan, Birleşmiş Milletler'in (BM) IGE verilerinden ve Dünya Ekonomik Forumu'nun (DEF) KCUE verilerinden elde edilmiştir. ${ }^{16-18}$ Araştırmaya ilişkin veriler 01.10.201931.10.2019 tarihleri arasında toplanmıştır.

Araştırma için $\mathrm{BOH}$ Raporu'ndaki verilerden; ülkelerin sosyoekonomik düzeyleri, bulaşıcı olmayan hastalıklar nedeniyle meydana gelen ölümlerin tüm ölümler içindeki yüzdesi olarak tanımlanan $\mathrm{BOH}$ mortalite oranı ve bulaşıcı olmayan hastalıklar nedeniyle meydana gelen 30-70 yaş ölümlerin tüm 30-70 yaş ölümler içindeki yüzdesi olarak tanımlanan prematür $\mathrm{BOH}$ mortalite oranı kullanılmıştır. ${ }^{16}$

Her yıl yayımlanan ve insani gelişmenin temel boyutlarını ölçmekte olan IGE; kişi başına düşen gayrisafi milli hâsıla (GSMH), beklenen öğrenim süresi, ortalama öğrenim süresi ve doğumda beklenen yaşam süresi değerleri ile hesaplanmaktadır. 0 ile 1 arasında değer alan bir endekstir. Endeks değerleri 1'e yaklaştıkça insani gelişmişlik artmaktadir. ${ }^{17}$

Kadın ve erkek eşitliğinin farkını inceleyen KCUE; ekonomik katılım ve firsat, eğitime ulaşım, sağlık ve sağ kalım, siyasi güçlenmeden oluşan dört parametre ile hesaplanan bir değerdir. 0 ile 1 arasında değer almaktadır. Endeks değerleri 1'e yaklaştıkça cinsiyet eşitsizliği azalmaktadır. ${ }^{18}$

Araştırmada kullanılan verilerin tamamı 2016 yılına aittir. Verilerin kıyaslanabilir olması açısından, analize dâhil edilen verilerin aynı tarihli olmaları önemsenmiştir. Karşılaştırmalarda kullanılması planlanan verilerin tamamına sahip olan 140 ülke araştırma kapsamına alınmış; 55 ülke ise verilerinde eksiklikler bulunması nedeniyle çalışma dışında bırakılmıştır.

\section{Verilerin Analizi}

Veri girişi, analizi ve rapor yazımı işlemleri bilgisayar ortamında gerçekleştirilmiştir. Analizler sırasında ortalama, standart sapma, minimum ve maksimum değerleri sayısal verileri özetlemede kullanılmıştır. Çalışmada; $\mathrm{BOH}$ mortalite oranları ve prematür $\mathrm{BOH}$ mortalite oranları ile IGE ve KCUE arasındaki ilişki; Spearman Korelasyon katsayısı (r) ile incelenmiştir. Elde edilen katsayıların değerlendirilmesinde $\quad 0,00-0,19 \quad$ aras1 önemsenmeyecek düzeyde düşük ilişki, 0,200,39 arası zayıf ilişki, 0,40-0,69 arası orta düzeyde ilişki, 0,70-0,89 arası kuvvetli ilişki ve 0,90-1,00 arası çok kuvvetli ilişki olarak kabul edilmiştir. Pozitif işaretli korelasyon katsayıları değişkenlerin birlikte artıp azaldığına, negatif işaretli korelasyon katsayıları ise değişkenlerden biri artarken diğerinin azaldığına veya tam tersine işaret etmektedir. ${ }^{19}$ Aralarında yüksek korelasyon bulunan değişkenler doğrusal regresyon analizi ile incelenmiştir. P'nin 0,05'ten küçük olduğu durumlar istatistiksel açıdan anlamlı kabul edilmiştir.

\section{Araştırmanın Etik Yönü}

Araştırmada insanla doğrudan temas olmadığından ve araştırma tüm kamunun açık erişiminin bulunduğu veriler üzerinden yapıldığından, etik ya da resmi herhangi bir izin alınmamıştır.

\section{Araştırmanın Güçlü Yönleri ve Kısıtlılıkları}

Araştırmanın bazı güçlü yönleri bulunmaktadır. Araştırma yerel ölçekli değildir. Araştırma kapsamına Dünya üzerindeki pek çok ülke (140) alınmıştır. Araştırmada kullanılan verilerin tamamı aynı yıla aittir. Araştırmada kullanılan veriler DSÖ, BM ve DEF'ten sağlandığı için; veri kalitesinin iyi olduğu düşünülmektedir.

Araştırmanın bazı kisıtlılıkları bulunmaktadır. Verilerinde eksiklikler 
bulunan 55 ülke kapsam dışında bırakılmıştır.

Araştırma birimi birey değil toplumdur.

\section{BULGULAR VE TARTIŞMA}

Araştırma kapsamına alınan 140 ülkenin \%15'i (n=21) düşük, \%20,7'si (n=29) düşükorta, \%29,3'ü $(n=41)$ yüksek-orta ve $\% 35$ 'i $(n=49)$ yüksek gelir düzeyine sahipti.
Toplam 140 ülkenin $\mathrm{BOH}$ mortalite oranları ortalamas1 $\% 72,385 \pm 20,758$ (Min:27, Max:95) idi. 30-70 yaş arası prematür $\mathrm{BOH}$ mortalite oranları ortalamas1 $\% 17,607 \pm 5,447$ (Min:8, Max:31) idi. Ülkelerin diğer bazı özellikleri Tablo 2'de sunulmuştur.

Tablo 2. Ülkelerin Araştırmaya Konu Olan Özellikleri

\begin{tabular}{|c|c|c|c|c|c|}
\hline $\begin{array}{c}\text { Ülkelerin } \\
\text { Gelir Düzeyi }\end{array}$ & Değişkenler & Ortalama & $\begin{array}{c}\text { Standart } \\
\text { Sapma }\end{array}$ & Minimum & Maksimum \\
\hline \multirow{6}{*}{ Düşük } & BOH Mortalite Oranı & 42,14 & 16,79 & 27,00 & 83,00 \\
\hline & 30-70 Yaş Arası Prematür BOH Mortalite Oranı & 20,76 & 3,16 & 13,00 & 25,00 \\
\hline & Kadın Prematür BOH Mortalite Oranı & 19,57 & 3,04 & 13,00 & 26,00 \\
\hline & Erkek Prematür BOH Mortalite Oranı & 22,24 & 3,97 & 14,00 & 33,00 \\
\hline & İGE & 0,50 & 0,078 & 0,41 & 0,67 \\
\hline & KCUE & 0,68 & 0,052 & 0,59 & 0,80 \\
\hline \multirow{6}{*}{ Düşük-Orta } & BOH Mortalite Oran1 & 63,69 & 18,71 & 29,00 & 94,00 \\
\hline & 30-70 Yaş Arası Prematür BOH Mortalite Oranı & 21,48 & 5,25 & 12,00 & 31,00 \\
\hline & Kadın Prematür BOH Mortalite Oranı & 18,86 & 4,76 & 11,00 & 28,00 \\
\hline & Erkek Prematür BOH Mortalite Oranı & 24,34 & 7,34 & 13,00 & 39,00 \\
\hline & İGE & 0,63 & 0,09 & 0,46 & 0,78 \\
\hline & KCUE & 0,67 & 0,06 & 0,52 & 0,79 \\
\hline \multirow{6}{*}{ Yüksek-Orta } & BOH Mortalite Oran1 & 77,71 & 16,51 & 27,00 & 95,00 \\
\hline & 30-70 Yaş Arası Prematür BOH Mortalite Oranı & 18,56 & 4,15 & 12,00 & 29,00 \\
\hline & Kadın Prematür BOH Mortalite Oranı & 14,73 & 3,56 & 9,00 & 30,00 \\
\hline & Erkek Prematür BOH Mortalite Oranı & 22,56 & 6,12 & 14,00 & 37,00 \\
\hline & İGE & 0,75 & 0,06 & 0,49 & 0,84 \\
\hline & KCUE & 0,69 & 0,04 & 0,59 & 0,77 \\
\hline \multirow{6}{*}{ Yüksek } & BOH Mortalite Oranı & 86,04 & 6,21 & 69,00 & 93,00 \\
\hline & 30-70 Yaş Arası Prematür BOH Mortalite Oranı & 13,16 & 4,12 & 8,00 & 25,00 \\
\hline & Kadın Prematür BOH Mortalite Oranı & 10,06 & 3,12 & 5,00 & 18,00 \\
\hline & Erkek Prematür BOH Mortalite Oranı & 16,59 & 6,04 & 10,00 & 37,00 \\
\hline & $\overline{\mathrm{I} G E}$ & 0,88 & 0,04 & 0,79 & 0,95 \\
\hline & KCUE & 0,72 & 0,06 & 0,58 & 0,87 \\
\hline \multirow{6}{*}{ Türkiye } & BOH Mortalite Oran1 & 89,00 & - & - & - \\
\hline & 30-70 Yaş Arası Prematür BOH Mortalite Oranı & 16,00 & - & - & - \\
\hline & Kadın Prematür BOH Mortalite Oranı & 11,00 & - & - & - \\
\hline & Erkek Prematür BOH Mortalite Oranı & 22,00 & - & - & - \\
\hline & İGE & 0,79 & - & - & - \\
\hline & KCUE & 0,62 & - & - & - \\
\hline \multirow{6}{*}{ Genel } & BOH Mortalite Oran1 & 72,39 & 20,76 & 27,00 & 95,00 \\
\hline & 30-70 Yaş Arası Prematür BOH Mortalite Oranı & 17,60 & 5,45 & 8,00 & 31,00 \\
\hline & Kadın Prematür BOH Mortalite Oranı & 14,68 & 5,26 & 5,00 & 30,00 \\
\hline & Erkek Prematür BOH Mortalite Oranı & 20,79 & 6,82 & 10,00 & 39,00 \\
\hline & İGE & 0,73 & 0,15 & 0,41 & 0,95 \\
\hline & KCUE & 0,69 & 0,06 & 0,52 & 0,87 \\
\hline
\end{tabular}

Araştırma kapsamında bulunan 140 ülkeden en düşük $\mathrm{BOH}$ mortalite oranına sahip olanlar Çad, Angola, Kenya ve
Mozambik iken; en yüksek orana sahip olan ülkeler Bulgaristan, Sırbistan ve Karadağ idi. 
Prematür $\mathrm{BOH}$ ölümlerinin en düşük olduğu ülkeler Japonya ve Kore; en yüksek olduğu ülke ise Yemen'di. Prematür BOH kadın ölümleri Kore'de en düşük ve Fildişi Sahili'nde en yüksekti. Prematür BOH erkek ölümleri İzlanda'da en düşük ve Moğolistan'da en yüksekti.

IGE en düşük olan ülke Çad ve en yüksek olan ülke Norveç'ti. KCUE en düşük ülke Yemen ve en yüksek ülke İzlanda idi.

Gelir durumu yüksek-orta olan Türkiye'nin BOH mortalite oranı \%89, 30-70 yaş arası prematür $\mathrm{BOH}$ mortalite oranı $\% 16$, kadın prematür $\mathrm{BOH}$ mortalite oran $\% 11$ ve erkek prematür $\mathrm{BOH}$ mortalite oran $1 \% 22$ idi. Türkiye'nin IGE 0,787 ve KCUE 0,623 idi (Tablo 2).

Ülkelerin $\mathrm{BOH}$ mortalite oranları ile IGE arasında pozitif yönlü, kuvvetli düzeyde ve anlamlı ilişki saptandı $(\mathrm{r}=0,781, \mathrm{p}<0,001)$. $\mathrm{BOH}$ mortalite oranları ile KCUE arasında pozitif yönlü, zayıf düzeyde ve anlamlı ilişki saptand $1 \quad(r=0,323, p<0,001)$. Değişkenlere ilișkin korelasyon katsayıları ve $\mathrm{p}$ değerleri Tablo 3 'te sunulmuştur.

Tablo 3. Değişkenler Arası İlişkilerin Boyutu

\begin{tabular}{lcc}
\hline Değişkenler & IGE(r/p) & KCUE(r/p) \\
\hline BOH Mortalite Oranları & $0,78 /<0,001 *$ & $0,32 /<0,001$ \\
\hline 30-70 Yaş Arası Prematür BOH Mortalite Oranları & $-0,65 /<0,001$ & $-0,31 /<0,001$ \\
\hline Kadın Prematür BOH Mortalite Oranları & $-0,82 /<0,001^{*}$ & $-0,39 /<0,001$ \\
\hline Erkek Prematür BOH Mortalite Oranları & $-0,47 /<0,001$ & $-0,21 / 0,014$ \\
\hline
\end{tabular}

*Yüksek korelasyona işaret etmektedir.

Korelasyon analizinde yüksek korelasyona $(>0,70)$ sahip değişkenler için doğrusal

regresyon analizi yapılmış (Tablo 4) ve saçılım grafikleri çizilmiştir (Şekil 1 ve 2).

Tablo 4. BOH Mortalite Oranı ve Kadın Prematür BOH Mortalite Oranı ile İGE'nin Doğrusal Regresyon ile İncelenmesi

\begin{tabular}{ll}
\hline \multicolumn{1}{c}{ BOH Mortalite Oranı ile İGE } & Kadın Prematür BOH Mortalite Oranı ile İGE \\
\hline $\mathbf{R}=0,87$ & $\mathbf{R}=0,80$ \\
\hline $\mathbf{R}^{2}=0,76$ & $\mathbf{R}^{2}=0,64$ \\
\hline $\mathbf{F}=435,18$ & $\mathbf{F}=245,80$ \\
\hline $\mathbf{p}<0,001$ & $\mathbf{p}<0,001$ \\
\hline Regresyon modeli $=-17,42+122,23 x \dot{I} G E$ & Regresyon modeli $=35,59-28,46 x \dot{I G E}$ \\
\hline
\end{tabular}

Araştırmamızda İGE ile tüm değişkenler arasında istatistiksel açıdan anlamlı ilişki saptanmıştır. İGE yüksek olan ülkelerde, BOH mortalitesi de yüksektir ve bu iki değer kuvvetli pozitif korelasyon göstermektedir. İGE yüksek olan ülkelerde 30-70 yaş arası kişilerin $\mathrm{BOH}$ nedenli ölümlerden daha az etkilendiği bulunmuştur. İGE yüksek ülkelerde kadınlar, erkeklere oranla prematür $\mathrm{BOH}$ mortalitesinden daha az etkilenmektedir. 


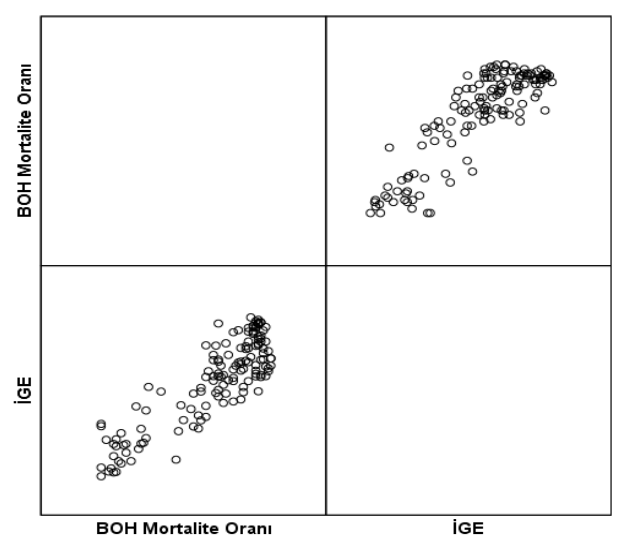

Şekil 1. BOH Mortalite Oranı ile İGE için Saçılım Grafiği

$\mathrm{Bu}$ durumlar İGE yüksek olan ülkelerde doğumda beklenen yaşam süresinin yüksek olması nedeniyle uzun yıllar yaşayan kişilerin $\mathrm{BOH}$ riskleriyle daha kolay karșılașmasıyla açıklanabilir. İGE yüksek ülkelerde bulaşıcı hastalıklar yüksek ölçüde kontrol altına alındığından, BOH riskleri daha ön planda olabilir. Ayrıca İGE yüksek olan ülkelerde İGE düşük olan ülkelere göre GSMH'nın daha yüksek olması; insanların fiziksel inaktivite, sağlıksız beslenme, sigara ve alkol kullanım olanaklarına daha kolay ulaşmasını sağlıyor olabilir. İGE yüksek ülkelerin, yüksek gelirlerinden sorumlu tutulabilecek endüstri ve sanayinin neden olduğu çevre kirliliği BOH mortalite oranlarını arttırabilir. Bununla birlikte İGE yüksek olan ülkelerde beklenen ve ortalama öğrenim süresi, İGE düşük ülkelere göre daha yüksektir. Daha fazla eğitim almış kişilerin BOH'lardan daha fazla oranda korunması beklenen bir sonuç iken; çalışmamızda bununla uyumlu bir bulguya ulaşılmamıştır. $\mathrm{Bu}$ durum kişilerin bir şeyi bilme oranlarıyla uygulama oranlarının her zaman birbirini tutmamasiyla ilişkilendirilebilir. İGE yüksek ülkelerde erkeklere kıyasla kadınların prematür $\mathrm{BOH}$ mortalitesinden daha az etkilenmeleri; kadınların eşitsizliklere daha duyarlı bir grup olmasıyla açıklanabilir.

Pervaiz ve Ercantan'in 2018'de yayımlanan çalışmalarında İGE yüksek olan ülkelerde, İGE düşük ve orta olan ülkelere göre hem $\mathrm{BOH}$ mortalitesi hem de prematür $\mathrm{BOH}$ mortalitesi daha düşük bulunmuştur. ${ }^{14}$

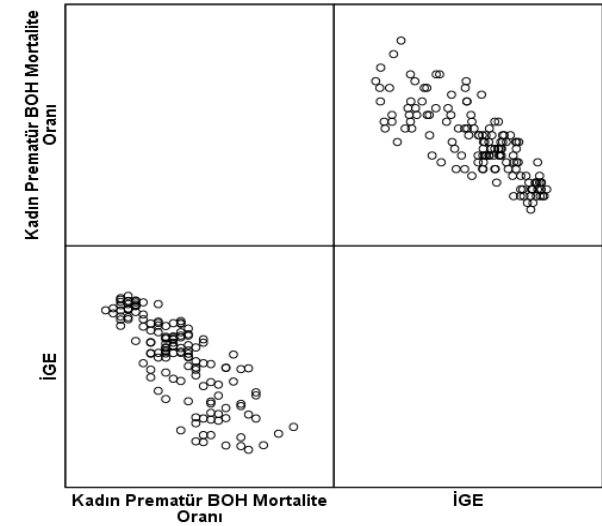

Şekil 2. Kadın PrematürBOH Mortalite Oranı ile İGE için Saçılım Grafiği

$\mathrm{Bu}$ sonuç araştırmamızda bulduğumuz sonuçtan bir miktar farklı görünmektedir. Durumun olası nedeni ilgili yıla ait (2015) oran ve endeks değerleri olabilir.

Araştırmamızda KCUE ile tüm değişkenler arasında istatistiksel açıdan anlamlı ilişki saptanmıştır. KCUE yüksek olan ülkelerde, $\mathrm{BOH}$ mortalitesi de yüksektir ve bu iki değer arasında zayıf pozitif korelasyon bulunmaktadır. KCUE düşük olan ülkelerde 30-70 yaş arası kişilerin $\mathrm{BOH}$ nedenli ölümlerden daha fazla oranda etkilendiği bulunmuştur. KCUE düşük ülkelerde kadınlar, erkeklere oranla prematür $\mathrm{BOH}$ mortalitesinden daha fazla etkilenmektedir. $\mathrm{Bu}$ bulgular, kadın ve erkek eşitliğinin sağlanamamasının sağlığı olumsuz etkilediğini göstermektedir.

Toplumsal cinsiyet eşitsizliğinin daha az belirgin olduğu toplumlarda $\mathrm{BOH}$ mortalite oranları yüksektir. Bu durum KCUE yüksek olan toplumların aşıyla, temel hijyen kurallarına uyumla, su ve besin sanitasyonuyla önlenebilecek bulaşıcı hastalıkların yüklerinden kurtulduklarını düşündürmektedir. Bütün ölümler içinde bulaşıcı hastalıkların payı azalınca, başa çıkmak için multisektöryel ve multidisipliner önlemlerin gerektiği $\mathrm{BOH}$ ve kazaların payı artmış olabilir. KCUE düşük olan, toplumsal cinsiyet eşitsizliğinin belirgin olduğu toplumlar ise bulaşıcı hastalık ve kaza risklerinin yanı sıra, yüksek prematür $\mathrm{BOH}$ ölümleriyle yüzyüzedirler. Eşitsizlik her iki 
cinsiyeti de etkilemektedir. Ancak kadınların prematür $\mathrm{BOH}$ ölüm oranları ile KCUE değerleri arasında, erkelerinkine kıyasla daha büyük bir korelasyon katsayısı hesaplanmış olması, her ne kadar iki ilişki de zayıf olsa bile, kadınların eşitsizlikten daha fazla etkilendiğini düşündürmektedir. $\mathrm{Bu}$ durum kadınların ekonomi, sağlık, eğitim ve siyaset alanında erkeklerle eşit firsatlar yakalayamadığına işaret ediyor olabilir.
Christiani ve arkadaşlarının 2016'da yayımlanan çalışmasında araştırmamızla paralel sonuçlara ulaşılmış olup toplumsal cinsiyet eşitsizliğinin kadınların $\mathrm{BOH}$ morbiditesini ve $\mathrm{BOH}$ risklerini daha fazla arttırdığı sonucuna ulaşılmıştır. ${ }^{15}$ Ayrıca DSÖ ve Uluslararası Diyabet Federasyonu ortak raporunda da toplumsal cinsiyet eşitsizliğinin BOH oranlarını etkilediği belirtilmektedir. ${ }^{20}$

\section{SONUÇ VE ÖNERILER}

Araştırma sonucunda; $\mathrm{BOH}$ ve prematür $\mathrm{BOH}$ mortalite oranları ile İGE ve KCUE arasında anlamlı ilişkiler saptanmıştır. İnsani gelişmişlik arttıkça ve küresel cinsiyet eşitsizliği azaldıkça; $\mathrm{BOH}$ ve prematür $\mathrm{BOH}$ mortalitesinin arttı̆̆ bulunmuştur. Küresel çapta bir sorun olan $\mathrm{BOH}$ ve prematür $\mathrm{BOH}$ mortalitelerini azaltmak ve önlemek için atılması gereken adımların uzun vadeler için hayata geçirilecek multisektöryel, multidisipliner ve küresel ölçekli planlar olması gerektiğini düşünüyoruz. Genel bir öneri olarak tüm bireylerin sağlıklı beslenmesinin sağlanması, yeterli fizik aktivite yapması, sigara ve alkolden uzak durması sağlanmalıdır. Her alanda kadın ve erkek eşitliğinin sağlanmasının; bütün insanların ekonomi, sağlık, eğitim ve siyaset alanında bugün ulaşabildiklerinden daha fazla ve daha eşit firsatlara kavuşmalarının yarar sağlayacağ1 görüşündeyiz.

\section{KAYNAKLAR}

1. Kocabas A. Küresel ve ulusal akciğer sağlığına en büyük tehdit sağlıkta eşitsizlik. (2014). Toraks Bülteni, 2, 9-14.

2. WHO and Commission on Social Determinants of Health Closing the gap in a generation. Geneva. (2008) https://www.who.int/social_determinants/final_report/csdh_fin alreport_2008.pdf Erişim tarihi: 04.11.2019

3. Ak N, Baran Aksakal FN, Özkan S. Eşitsizlikler ve bulaşıcı hastalıklar. (2018). Türkiye Klinikleri, 1, 55-60.

4. Kawachi I, Subramanian SV, Almeida-Filho N. A glossary for health inequalities. (2002). J Epidemiol Community Health, 56, 647-652.

5. Akın A. Eşitsizlikler ve sağlık. (2018). Türkiye Klinikleri, 1, 1-5.

6. Whitehead M, Dahlgren G. Concepts and principles for tackling social inequities in health: Levelling up Part 1. (2006). WHO Collaborating Centre for Policy Research on Social Determinants of Health University of Liverpool. https://www.euro.who.int/_data/assets/pdf_file/0010/74737/E 89383.pdf Erişim tarihi: 04.11.2019.

7. McGinnis JM, Williams-Russo P, Knickman JR. The case formoreactive policy attention to health promotion (2012).Health Affairs, 21, 78-93.

8. Kuznetsova, D. Healthyplaces: Councils leading on public health (2012). London: New Local Government Network http://www.nlgn.org.uk/public/2012/healthy-places-councilsleading-on-public-health/ Erişim tarihi: 04.11.2019.

9. Bunker JP, Frazier HS, Mosteller F. Society and Health. (1995) New York: Oxford University Press.

10. Güler Ç, Akın L. Halk Sağlı̆ğ Temel Bilgiler. 1. Cilt. (2015). Ankara: Hacettepe Üniversitesi Yayınları. 3. Basım.

11. WHO. Fact Sheets. The top 10 causes of death. (2018) https://www.who.int/news-room/fact-sheets/detail/the-top-10causes-of-death Erişim tarihi: 08.11.2019.
12. WHO. Global Health Observatory Top 10 Causes of Death Situation and Trends. (2018). https://www.who.int/data/gho/data/themes/topics/causes-ofdeath/GHO/causes-of-death Erişim tarihi: 08.11.2019.

13. Ünal B. Eşitsizlik kavramı ve bulaşıcı olmayan hastalıklar. (2018). Türkiye Klinikleri, 1, 61-67.

14.Pervaiz R, Ercantan Ö. The burden of non-communicable diseases in relation to economic status of countries. (2018). Biomed Res Ther, 5 (1), 1967-1974.

15. Christiani Y, Byles JE, Tavener M, Dugdale P. Gender inequalities in noncommunicable disease risk factors among Indonesian urban population. (2016). Asia Pacific Journal of Public Health, 28 (2), 134-145.

16. WHO. Global Status Report on Noncommunicable Disease. (2018).

https://www.who.int/publications/i/item/9789241514620 Erişim tarihi: 01.10.2019.

17. UNDP. Human Development Indices and Indicators: 2018 Statistical Update. (2018). http://hdr.undp.org/sites/default/files/2018_human_developmen t_statistical_update.pdf Erişim tarihi: 01.10.2019.

18. World Economic Forum. The Global Gender Gap Report. (2016). http://www3.weforum.org/docs/GGGR16/WEF_Global_Gende r_Gap_Report_2016.pdf Erişim tarihi: 01.10.2019.

19. Alpar R. Spor, Sağlık ve Eğitim Bilimlerinden Örneklerle Uygulamalı İstatistik ve Geçerlik-Güvenirlik. 3. Baskı. (2014). Ankara; Detay Yayınc1lık.

20. Pan American Health Organization (Regional Office of the WHO) and International Diabetes Federation. NonCommunicable Diseases and Gender. (2011) https://www.paho.org/hq/dmdocuments/2012/PAHO-FactsheetGender-English.pdf Erişim tarihi: 01.05.2020. 